Res Pública Revista de Historia de las Ideas Políticas

ISSN: $1131-558 \mathrm{X}$

https://dx.doi.org/10.5209/rpub.75740

\title{
De la naturaleza de las cosas de Lezra
}

\author{
Erin Graff-Zivin ${ }^{1}$
}

Recibido: 27-04-2021 / Aceptado: 25-08-2021

Resumen. Este ensayo busca trazar una genealogía defectuosa de varias escenas de lectura en la obra de Jacques Lezra. Se enfoca en la lectura como práctica metodológica salvaje que conjuga -de manera inesperada, contraintuitiva, e indisciplinadaobjetos, discursos, y modalidades conceptuales. Se analiza una selección de escenas de lectura de Materialismo salvaje y República salvaje para identificar en ellas un pensamiento estético-político que imagina corrientes subterráneas y deconstruye conceptos como soberanía, institución, y normatividad, enfatizando su carácter defectuoso.

Palabras clave: lectura; institución; deconstrucción; materialismo; soberanía.

\section{[en] On the Nature of Lezra's Things}

Abstract. This essay seeks to trace a defective genealogy of scenes of reading in the work of Jacques Lezra. It focuses on reading as a wild methodological practice that combines -in an unexpected, counterintuitive, and undisciplined wayobjects, discourses, and conceptual modalities. A selection of reading scenes from Wild Materialism and República salvaje is analyzed in order to identify in them an aesthetic-political thinking that imagines undercurrents and deconstructs concepts such as sovereignty, institution, and normativity, emphasizing their defective qualities.

Keywords: Reading; Institution; Materialism; Sovereign.

Sumario. Introducción. 1. Instituciones aleatorias. Primera escena: Lezra, lector de Lucrecio, lector de los sentidos. Segunda escena: Lezra, lector de Marx, lector de Lucrecio. 2. Ética háptica. Tercera escena: Lezra, lector de Levinas, lector de Sófocles. De... En... Como... Bibliografía.

Cómo citar: Graff-Zivin, E. (2022). De la naturaleza de las cosas de Lezra. Res Pública. Revista de Historia de las Ideas Políticas, 25(2), 3-9.

\section{Introducción}

Nos encontramos en un momento político-intelectual en el cual debatimos con frecuencia el uso de los conceptos clásicos, y modernos, del pensamiento político. Según pensadores deconstructivos (pienso, por ejemplo, en el pensamiento "después del sujeto" de Jacques Derrida o Jean-Luc Nancy) y posthegemónico-infrapolíticos (Alberto Moreiras, Jon Beasley-Murray, Gareth Williams, o Sergio Villalobos-Ruminott), estamos frente al agotamiento de conceptos que han dominado el territorio intelectual, tales como "sujeto", "soberanía", "hegemonía", "institución", y "normatividad". Hay otros que buscan defender los mismos conceptos como único camino posible a la emancipación: se me ocurren Alain Badiou y Étienne Balibar, aunque este último tiene su lado derrideano. Hay otros, y otras, que buscan trazar corrientes subterráneas que desestabilizan o deconstruyen los conceptos desde adentro (pienso en Judith Butler y James
Martel, que insiste en misrecognition o misinterpellation como central a la experiencia de la interpelación ideológica althusseriana). La obra de Jacques Lezra que responde a, y se nutre de, todos los pensadores que acabo de mencionar- enfatiza el rasgo defectuoso de los conceptos tanto políticos como éticos, además de la extraña relación entre ellos. El presente ensayo busca trazar una genealogía defectuosa de varias escenas de lectura en la obra de Lezra, enfocándose en la lectura como práctica metodológica salvaje que conjuga -de manera inesperada, contraintuitiva, e indisciplinadaobjetos, discursos, y modalidades conceptuales. Analizo una selección de escenas de lectura de Materialismo salvaje y República salvaje para identificar en ellas un pensamiento estético-político que imagina corrientes subterráneas y deconstruye conceptos como soberanía, institución, y normatividad, enfatizando su carácter defectuoso y aleatorio. El ensayo se divide en dos partes, "Instituciones aleatorias" y "Ética háptica", en las cua- 
les propongo lecturas multiplicadas de Lucrecio, Marx, y Althusser, de Sófocles, Shakespeare, y Levinas: lecturas materialistas-sensoriales que producen un pensar estético-ético-político salvaje.

\section{Instituciones aleatorias}

\author{
Porque si el aire de extranjero clima \\ De peligrosa cualidad dotado \\ Se muda y va viniendo hacia nosotros, \\ Se arrastra lentamente como nube \\ Altera y muda todas las regiones \\ De la atmósfera por donde camina: \\ Cuando llegó a la nuestra últimamente \\ La corrompe, y así se la asimila \\ Y nos la hace contraria: se derrama \\ Este nuevo contagio... \\ se queda colgado algunas veces \\ Su contagio en el aire, y no podemos \\ Respirar este fluido mezclado \\ Sin sorber su infección al mismo tiempo. \\ Lucrecio $^{2}$
}

Podría haber acontecido de otra manera.

Este es el tema de múltiples series de televisión norteamericanas recientes que buscan imaginar una realidad alternativa si Trump hubiera perdido las elecciones en noviembre de 2016. Quizás 27 millones de norteamerianos no se hubieran enfermado del coronavirus. Quizás 465 mil personas todavía estarían vivas ${ }^{3}$. Pero quizás tampoco hubiéramos visto el renacimiento de movimientos feministas y anti-racistas, de \#MeToo a \#BlackLivesMatter: y esto solamente para hablar de los Estados Unidos. En Chile las cifras oficiales del virus son parecidas, y las no oficiales peores todavía. Pero si no hubiera ganado Piñera, cuyo gobierno después mintió sobre la cantidad de enfermos y muertos, ¿hubiera acontecido el estallido social, antes de que la pandemia cerrara el país? ¿Hubiera ganado la convención constituyente? Las instituciones que parecían sólidas -la policía, la constitución- no se hubieran puesto abiertamente en cuestión, heridas, abiertas al cambio o a la abolición. ¿Y si Pedro Sánchez no hubiera formado una coalición con Unidas Podemos en enero de 2020, que ganó con una diferencia de dos diputados? La actualidad política parece gobernada por contingencias, como si lo aleatorio fuera la única condición de la política.

Podría haber acontecido de otra manera.

Esta es la ley de la contingencia que nos describe Lucrecio, en su poema epicureo De rerum natura, objeto de estudio -entre otras cosas- del libro República salvaje: De la naturaleza de las cosas escrito por Jacques Lezra. En la lluvia de átomos que cae, uno u otro encuentro, uno u otro choque atómico, podría no haber tenido lugar. Podría el aire no haber llevado el contagio desde Egipto a

T. Lucrecio Caro, De la naturaleza de las cosas, trad. D. José Marchena, Alicante, Biblioteca Virtual Miguel de Cervantes, 1999, Canto VI, 1650-1666. http://www.cervantesvirtual.com/obra-visor/dela-naturaleza-de-las-cosas-poema-en-seis-cantos--0/html/.

Con cada revisión del presente ensayo, se doblaba los números; estas últimas cifras son del 9 de febrero de 2021.
Atenas, tal como lo describe Lucrecio en los versos que me sirven de epígrafe, para devastar al pueblo ateniense siglos antes de la composición del poema. En República salvaje, Lezra vuelve al poema para pensar, con Lucrecio, no solamente la naturaleza de las cosas -ni la coincidencia epidemiológica respiratoria, ni la caracterización xenofóbica de ella- sino también para plantear que el pensamiento de y sobre las cosas, los objetos, nos puede ayudar a imaginar nuevas asociaciones políticas, nuevas instituciones defectuosas que no se basen en las ficciones relacionadas de la representación y la identificación.

El último libro de Lezra no es ajeno a su obra anterior, sino que emerge como el último en una serie de libros que busca desestabilizar las instituciones fuertes, y los conceptos políticos que las sostienen. Wild Materialism: The Ethic of Terror and the Modern Republic (traducido como Materialismo salvaje: La ética del terror y la república moderna), fue el primer libro de lo que iba a ser una trilogía en inglés sobre conceptos políticos defectuosos; Untranslating Machines: A Genealogy for the Ends of Global Thought y On the Nature of Marx's Things: Translation as Necrophilology, que iban a formar el "segundo" libro pero que luego se dividieron en dos; y Defective Institutions, que está en camino; más República salvaje, publicado en castellano, que incluye la traducción del primer capítulo del libro sobre Marx y anticipa las tesis por venir en Defective Institutions. En Materialismo salvaje, de 2010, Lezra plantea el concepto, o paraconcepto, del "terror", experiencia de la cual marca los residuos de la secularización incompleta del cuerpo soberano que asedia a la modernidad europea, y se pregunta si puede haber una ética y una política que guarden la experiencia del terror, proponiendo la idea de una república sádica, terrible, y el principio metodológico del materialismo salvaje como práctica.

Pero podría haber acontecido de otra manera.

En los agradecimientos de Materialismo salvaje, al cual volveré con más atención abajo, Lezra explica que ya había terminado un borrador del manuscrito en agosto de 2001, justo antes del 11 de septiembre norteamericano, y que lo tuvo que reescribir a causa de eventos tanto políticos como personales. Lo aleatorio invade la propia experiencia de la escritura del libro, que no se publica hasta casi nueve años más tarde. En la década que sigue (20102020), profundiza el método que empieza a desarrollar en Materialismo salvaje, en el cual la filología -entendida por muchos como una disciplina moribunda, o muerta, conservadora o hasta fascista- viene a desempeñar un papel inesperado en el pensamiento político radical. Lezra, que se doctoró en letras, se especializó en la literatura de la temprana modernidad hispana e inglesa, Cervantes y Shakespeare, entre otros. Como alumno doctoral en Yale, estudió con Roberto González Echevarría (pero también con Jacques Derrida y Paul de Man), y llega a la filosofía política -el pensamiento de Louis Althusser y Étienne Balibar, entre otros- varios años después. "La corriente subterránea del materialismo del encuentro", el materialismo aleatorio y salvaje, empiezan a cobrar fuerza en su trabajo, pero la lectura cuidadosa, meticulosa de textos tanto los literarios como los filosóficos- permanece siempre como nucleo metodológico de su escritura. 
Warren Montag indica que la conjugación de pensamiento materialista y lectura deconstructiva no es tan rara como podría parecer: en su libro Althusser and His Contemporaries, plantea que el método de lectura sintomática en Althusser no involucra la afirmación ni la negación de una u otra doctrina filosófica, como si fuera unitaria, sino que consiste en "«trazar lineas de demarcación desde adentro», hacer visible y palpable la presencia de fuerzas conflictivas dentro de un texto que puede parecer coherente, y aumentar e intensificar sus contradicciones"4. Según Montag -y concuerdo con su diagnóstico- tal método althusseriano está indudablemente influido por la obra de su amigo Derrida, quien describió "el movimiento de la deconstrucción" como el acto de habitar estructuras desde su interioridad: "obrando necesariamente desde el interior, extrayendo de la antigua estructura todos los recursos estratégicos y económicos de la subversión, extrayéndoselos estructuralmente, vale decir sin poder aislar en ellos elementos y átomos, la empresa de desconstrucción siempre es en cierto modo arrastrada por su propio trabajo"s.

Lectura atómica. En República salvaje, Lezra vuelve a la poética atómica lucreciana no solamente para analizar los temas de la percepción sensorial, sino también para habitar y pensar la estructura de sus versos, e imaginar estructuras, instituciones políticas análogas. Ahora bien, no es intuitivo tratar al poema como filosofía política, y Lezra lo reconoce: "Son pocos quienes opinan que deberíamos abordar el poema de Lucrecio como un tratado de filosofía política", dice ${ }^{6}$. Propone, en lugar de leer De rerum natura como teoría política, aproximarlo como "una poética para la extemporánea república salvaje" que se desvía "de la concepción clásica de la política"”.

La lectura detenida viene a ser método y también argumento en República salvaje. Mediante estas escenas de lectura $-\mathrm{y}$ tendré tiempo para detenerme en solamente dos de ellas- Lezra busca "derogar el concepto de las instituciones fuertes, de las instituciones en apariencia coherentes, que representan y administran los intereses del sujeto político en tanto este se identifica en y a través de ellas; y pensar, en cambio, en una república hecha de, y con, instituciones defectuosas, materiales". Después de analizar estas escenas, volveré, en la segunda parte del presente ensayo, a Materialismo salvaje para considerar una última escena de lectura, escena que anticipa la cuestión sensorial en República salvaje, y que nos permitirá re-leer este último desde una perspectiva ética.

\section{Primera escena: Lezra, lector de Lucrecio, lector de los sentidos}

Lucrecio describe la relación entre los sentidos y los átomos, imperceptibles en sí, pero perceptibles solo cuando chocan, se agrupan y adquieren estatus de

L. Althusser, "Lenin and Philosophy" 63, citado en W. Montag, Althusser and His Contemporaries, Durham y Londres, Duke University Press, 2013, p. 6 (traducción mía).

J. Derrida, De la gramatología, trad. Oscar del Barco, México, Siglo XXI Editores, 1979, pp. 32-33.

6 J. Lezra, República salvaje: De la naturaleza de las cosas, Santiago de Chile, Ediciones Macul, 2020, p. 31.

Ibidem, p. 51.

Ibidem, p. 13. objeto. Para ilustrar el punto sobre los átomos existentes pero imperceptibles, Lucrecio emplea la figura retórica de la analogía: igual que las motas de polvo que flotan en el aire pero que son invisibles hasta que entre el haz de luz para que las veamos, las simulacra (láminas, membranas materiales imposiblemente finas que se desprenden constantemente del objeto, sin cambiar en nada a éste), en cuanto tocan el cuerpo, producen efectos que llamamos sentidos (tacto, visión, oído, etc.). Esta percepción sensorial es, según Lucrecio, en cada caso verdadera: los sentidos no mienten. Sin embargo y al mismo tiempo, los sentidos pueden contradecirse. Estas contradicciones, el choque de "dos verdades encontradas", son lo que le interesa a Lezra, quien busca en ellas el fundamento de sus instituciones defectuosas, de sus instituciones, y cuerpos, incoherentes.

Según Lucrecio, el error viene no de los sentidos sino de la facultad mental, del pensar, de la idea, o de la interpretación de las verdades percibidas (correctamente) por los sentidos. También podríamos llamar a esta labor errónea, equivocada, el acto de leer. Y en la lectura de Lezra de la lectura que se encuentra en Lucrecio, la analogía entra a desempeñar el papel de la identificación-desidentificación simultánea. La analogía pretende buscar lo común, lo idéntico, pero solo puede llevarse a cabo con dos objetos no idénticos. "La estructura de la analogía es como el haz de la luz que cae en el mundo vacío para re-presentárnoslo a su contraluz", escribe Lezra, empleando la estructura analógica que describe ${ }^{9}$. No estamos muy lejos de la visión y la ceguera de Paul de Man: lo que Lucrecio pretende eliminar del terreno de lo verdadero -el error- entra, vuelve, mediante la figura retórica de la analogía. Y la no coincidencia, el error, que surge, y se da a comprender en tanto efecto y condición de, la lectura detenida (close reading en inglés), ahora aparece como concepto político defectuoso.

Pero, ¿qué tienen que ver los sentidos con las instituciones políticas? Lezra propone un camino posible: "El sentido de la vista es parte", sugiere, "de la república de los sentidos, y también, parte de la aristocracia o de la instancia soberana que gobierna la república de los sentidos" ${ }^{10}$. Entonces, si puede haber dos verdades encontradas, si la verdad no es unitaria, tampoco lo es la soberanía. Cuando el tacto y la visión presentan verdades contradictorias, "la soberanía del campo fenoménico, y del campo de los sentidos, se está condensando en dos principios: el de la visión y el del tacto, que entran en juego dinámico, conjunto. Este momento explica cómo puede haber dos principios, y no uno"11. La propuesta de unos sentidos no soberanos, que se lleva a cabo mediante la analogía, y la subsecuente lectura de ella, abren la posibilidad imaginaria, conceptual, de otra política, otra soberanía, y otras instituciones políticas: incoherentes, contradictorias, aleatorias, salvajes.

\footnotetext{
Ibidem, p. 106

$10 \quad$ Ibidem, p. 164.

$11 \quad$ Ibidem, p. 172.
} 
Segunda escena: Lezra, lector de Marx, lector de Lucrecio

"De la naturaleza de las cosas de Marx", el sexto capítulo de República salvaje, cuenta la historia del joven Marx, quien, mientras escribe su tesis doctoral en Londres, compila cuadernos de apuntes sobre Lucrecio y el pensamiento epicureo. En el cuarto cuaderno de los Apuntes sobre la filosofía epicúrea, Marx -heredero heterodoxo de la corriente subterránea del materialismo del encuentro- incluye una larga lista de citas de Lucrecio, diciendo que "no se puede hacer sino un pequeño uso de Lucrecio"12. Pero a pesar de - o quizás debido a- este "pequeño uso", Marx parece tomar inspiración de los versos poéticos lucrecianos. Lezra muestra cómo el joven Marx "parece autorizado por el vigor y la inteligencia del verso poético para extender sus propias alas literarias, y para entregarse a antítesis climatológicas, mitologías, antropomorfismos y símiles épicos: "Así como en la primavera la naturaleza se tiende desnuda»", escribe Marx, refiriéndose a Lucrecio, según nos cuenta Lezra, a quien yo, ahora, me pongo a leer, "«mostrando todos sus en Cantos [sic], como segura de su victoria, mientras que en invierno esconde sus vergüenzas y desnudeces bajo el manto de la nieve y el hielo, así Lucrecio, dueño y señor poético del mundo, fresco, lozano, intrépido, se distingue del pacato Plutarco, quien envuelve su pequeño yo bajo la nieve y el hielo de la moral»"13.

Mediante la narración poética de la experiencia de la desnudez, de la exposición, Marx se expone a sí mismo, se deja exceder a sí mismo. Dejándose ser elevado, expuesto, por la belleza de los versos de Lucrecio -por ejemplo por la aliteración que, según Paul Friedländer, "por su propio sonido y ritmo hacen cosquillas al oído, como las motas brillan para los ojos"- la filosofía política de Marx (como disciplina, como género) también se expone a ser tocada, a que la sometan al suplicio de las cosquillas ${ }^{14}$. La soberanía disciplinaria se expone como ficción, y la disciplina de la filosofía (tanto como los conceptos producidos por ella) se encuentra simultaneamente debilitada y fortalecida mediante la relación con la exterioridad: aquí, el afuera poético. Marx, en su exposición a Lucrecio mediante la experiencia de la lectura, encuentra en Lucrecio, en su lectura de Lucrecio, "una forma de registrar cómo el «pequeño Yo» del filósofo no logra coincidir consigo mismo" $"$.

Las multiplicidades reconocidas y suprimidas, el diferendo Marx, o marx con letra minúscula, añade otra capa de sentido a la idea althusseriana de la corriente subterranea: hay corrientes subterraneas, secretas, de una tradición, de la tradición filosófica en particular, pero también las hay en los mismos pensadores. Gracias a República salvaje, culminación pero no fin de la obra de Lezra, podemos atestiguar los puntos ciegos y secretos de Marx, de Lucrecio, de nosotros mismos, y de nuestras instituciones, cuyos defectos ofrecen la única

12 K. Marx y F. Engels, Werke B.40, p. 145, citado en J. Lezra, República salvaje, op. cit., p. 206.

13 K. Marx, Escritos de juventud, p.113, citado en en J. Lezra, República salvaje, op. cit., p. 211.

14 J. Lezra, República salvaje, op. cit., p. 235.

15 Ibidem, p. 245. promesa de nuevas formas, nuevas subjectividades, nuevas revueltas $\grave{a}$-venir. Esta es la naturaleza de las cosas de Lezra.

No podría haber acontecido de otra manera.

\section{2. Ética háptica}

Pero, ¿de dónde viene el interés en el sentido del tacto, en la fascinación por la analogía en el pensamiento de Jacques Lezra? ¿Qué papel desempeña en el pensar materialista salvaje, y cómo podemos volver a leer $\mathrm{Ma}$ terialismo salvaje desde esta perspectiva táctil, en la cual el tacto se entiende mediante la lectura, una lectura que toca y se deja tocar, de forma analógica? Por último, ¿qué nos enseña sobre la tarea de la interpretación dentro de la llamada "república de los sentidos" y su ética de terror? Volvamos a Materialismo salvaje, libro en que los sentidos no figuran como motivos principales, pero en cuyas páginas podemos empezar a trazar la metodología sensorial-interpretativa que deviene tema explícito en República salvaje. Si en Marx atestiguamos, mediante nuestra lectura de Lezra, la palpable calidad relacional de la lectura, la lectura como encuentro y exposición (Marx se deja tocar por los versos de Lucrecio), propongo considerar otra escena multiplicada de lectura lezraica -ahora de Levinas- que, por su parte, alude al mito de la túnica de Neso.

El mito es quizás mejor conocido por Las traquinias de Sófocles, pero ha sido adaptado, traducido o citado por muchísimos artistas, de Dante a Shakespeare, y a muchos géneros, del teatro a películas de Disney y hasta videojuegos. El mito, como la túnica misma, se pasa de mano en mano, con efectos impredicibles. Llega a las manos de Lezra de manera inesperada, indirecta. En general se ha leído la obra de Lezra (en el presente número especial, y más ampliamente) como filosofía política o crítica literaria. No es común referirse a su trabajo como pensamiento ético, a pesar de que la segunda mitad del título de Materialismo salvaje es La ética del terror y la república moderna. ¿Qué papel desempeña la "ética" en la constitución de la república? ¿Cómo se tocan el pensamiento ético y político en la obra de Lezra? Para empezar a responder a estas preguntas, consideraré una última escena de lectura, en la cual la filosofía ética levinasiana se expone como constitutivamente $-\mathrm{y}$ contraintuitivamente- violenta.

\section{Tercera escena: Lezra, lector de Levinas, lector de Sófocles}

"Un vestido es ante todo un cuerpo".

Emanuele Coccia

Es curioso, no que Lezra incorpore a Levinas en su discusión del republicanismo radical (aunque Levinas no menciona ni el republicansimo ni el terror), sino que elija frases bastante opacas, marginales, de Autrement qu'être para ofrecer una definición de la noción de responsabilidad. Escribe Lezra: 
La célebre y estupendamente reticente definición de la responsabilidad que da Emmanuel Levinas dice así: "Una responsabilidad anterior a todo compromiso libre, el unomismo fuera de todos los tropos de la esencia, sería la responsabilidad por la libertad de los otros. La irremisible culpabilidad respecto al prójimo es como la túnica de Neso de mi piel"16.

El pasaje de Levinas es raro, hasta marginal, pero subraya algo suprimido en los estudios convencionales de la obra del filósofo lituano: el caracter sumamente violento de la experiencia ética. Si se ha escrito bastante sobre la ética del cuerpo, del tocar (pienso en Ricoeur, Irigaray, Nancy, Derrida...), se suprime o se eclipsa la experiencia terrorífica del tocar, incluso del tocarse a sí mismo (como Karen Barad enfatiza en su brillante trabajo sobre el entrelazamiento cuántico [quantic entanglement], en el que asocia el "auto-tocar" en la teoría cuántica con la ética levinasiana, en particular, la idea del otro-dentro-del-mismo). En cambio, Lezra enfatiza el dolor, la tortura que experimenta Heracles después de recibir el regalo o el don (de la muerte, para decirlo con Derrida) de su tercera esposa Deyanira: la túnica envenenada con la sangre del centauro Neso.

Este regalo, recordemos, es fruto de luchas y envidias, de la economía de los afectos en el horizonte trágico clásico. Deyanira, que pretende reconquistar la atención y pasión de su marido Heracles, decide usar la túnica de Neso, que supuestamente tiene poderes mágicos. Neso, que murió víctima de una flecha envenenada lanzada por Heracles, ahora puede vengarse al envenenar el manto con su sangre. El efecto es inesperado: al ponerse la túnica Heracles, empieza a sentir un dolor tortuoso, y ve que el manto se ha adherido a su piel, quemándola. Es esta experiencia táctil, del contacto inseparable y violento entre piel y manto, que le interesa a Levinas, y luego a Lezra.

\section{De...}

Pero, ¿por qué? ¿Qué tienen que ver los temas griegos clásicos de la venganza, la tragedia, con la responsabilidad ética, y cómo se relacionan con la noción de la república moderna? Para Lezra, el pensamiento levinasiano ayuda a articular un concepto de normatividad no clásica, un concepto excesivo o defectuoso de normatividad, además de exponer la naturaleza excesiva o defectuosa de los conceptos (políticos) clásicos. Busca esta articulación-exposición mediante una cuidadosa lectura de la túnica, enfatizando la doble ambivalencia del "de" de Levinas ("La irremisible culpabilidad respecto al prójimo es como la túnica de Neso de mi piel"). La túnica como parte o extensión de la piel -que es parte, o extensión, o bien exceso, del $\operatorname{ser}^{17}$.

16 J. Lezra, Materialismo salvaje: La ética del terror y la república moderna, trad. Javier Rodríguez Fernández, Madrid, Biblioteca Nueva, 2012, p. 53.

17 "La corporeidad que el vestido encarna existe antes que todo como un espacio vacío, como algo que debe ser ocupado por una cierta porción de mundo, algo en lo que todo puede hacer las veces de nuestra fanera. El vestido es sobre todo la técnica que permite transformar cualquier objeto en piel” (E. Coccia, La vida sensible, trad.
Apréciese, en primer lugar, ese poco elegante sintagma, casi en aposición, "de mi piel": la cláusula traduce "comme la tunique de Nessus de ma peau", donde se captura con inteligencia la doble ambivalencia del "de" de Levinas: la responsabilidad es como la túnica, que es lo que mi piel es (y esta piel-túnica, la traza de la sangre emponzoñada de otro y del amor de otro, está irremisible y fatalmente sujeta al otro yo que yace bajo esta piel-túnica), o la responsabilidad es como la túnica que reviste mi piel (que yo llevo puesta sobre mi piel), la piel de mi piel, una envoltura, un refugio, una forma exterior, o bien un sustituto, un tropo o una figura que vela y revela la forma de mi piel, un tropo de la esencia ${ }^{18}$.

La ambivalencia sintagmática-retórica revela una concepción bastante heterodoxa de la ética, o de la responsabilidad para/con el otro. Viendo con ojos literarios, prestando atención a la rara estructura preposicional, Lezra demuestra que, para Levinas, la responsabilidad es pre-posicional.

En...

Volvamos a Levinas, justo antes de las frases que cita Lezra, donde medita sobre la expresión dans sa peau. "La expresión «en su piel» no es una metáfora del en $s i$ ", escribe Levinas, "se trata de una recurrencia en el tiempo muerto o el entretiempo que separa la inspiración y la expiración, la diástole y sístole del corazón que late sordamente contra la pared de su piel. El cuerpo no es tan sólo imagen y figura, sino que es el en-sí-mismo de la contracción de la ipseidad y de su estallido"19. En estas líneas, Levinas describe la rara presencia del otro en el mismo, la exterioridad interna que subvierte o imposibilita cualquier noción de esencia, ipseidad, o autonomía. No se puede separar el otro del yo, como tampoco se pueden separar, sin violencia suicida, la túnica de Neso de la piel de Heracles. El otro es "el corazón" del ser; dicho de otra forma, el sujeto no preexiste al otro, sino que es constituido por él.

Es más: estas líneas sirven como comentario sobre el uso del lenguaje figurativo, práctica a la cual Levinas ha expresado resistencia y hasta rechazo. "No es una metáfora", dice, "no es tan sólo imagen y figura". Si en "La realidad y su sombra" (1948), un ensayo temprano del pensador ético, Levinas denuncia el totalitarismo de las formas estéticas, sobre todo en la pintura, en De otro modo que ser recurre, una y otra vez, al lenguaje figurativo para intentar articular un pensamiento ético que no se encuentre aprisionado por el lenguaje ontológico (respondiendo, en parte, a la crítica de Jacques Derrida en "La violencia y la metafísica"). Sin embargo, no lo hace sin expresar una cierta ambivalencia ("no es" o "no es tan sólo"). Y esta ambivalencia encuentra "forma" o expresión en la rara imagen (y su rara sintaxis) de "la túnica de Neso de mi piel". En manos de Lezra empezamos a ver nuevas capas de sentido de dicho lenguaje

María Teresa D’Meza, Buenos Aires, Argentina, Marea, 2011, p. 120).

18 J. Lezra, Materialismo salvaje, op. cit., p. 55.

19 E. Levinas, De otro modo que ser, o más allá de la esencia, Salamanca, Editoriales Sígueme, 2003, p. 176. 
figurativo levinasiano, y sus implicaciones para una ética del terror.

\section{Como...}

Además de las preposiciones "de" y "en", podemos considerar el "como" levinasiano ("La irremisible culpabilidad respecto al prójimo es como la túnica de Neso de mi piel") como suplementario a la tesis de Lezra que "la responsabilidad es pre-posicional" ${ }^{20}$. Aunque Lezra no se enfoca en la estructura analógica de la túnica de Neso en Levinas, sí analiza la posibilidad del "como" (like) como concepto político varios años después en un ensayo inédito ${ }^{21}$. Quisiera detenerme - precipitada e irresponsablemente- en uno o dos puntos de ese texto (que, por su parte, se nutre de la lectura de otro texto, Hamlet), antes de concluir. Entre los posibles sentidos del like como concepto político (algunos de los cuales funcionan solamente, o mejor, en inglés), Lezra subraya lo com-ún de un grupo político -de una asociación socio-económica o de un grupo de interés (de deseos o likes en común)- en que uno es com-o los demás, en que lo común sirve como base o fundación para la asociación política. Aquí, la pertenencia se basa en la semejanza.

Pero pronto nos encontramos en una situación complicada al reconocer las diferencias que se habrían de suprimir o borrar para poder actuar como grupo unido, como si la colección de intereses o de interesados parecidos fuera una colectividad unitaria. Lezra insiste en que esta contradicción o aporía, en la que la diferencia se opone a la identidad, no tiene por qué estructurar las relaciones sociales (o las instituciones), y propone, mediante el análisis retórico-literario del concepto "como" (like), una teoría de la organización política que se base en la incoherencia. "Un símil tendrá dos términos en trémula proximidad, pero la afirmación de una identidad metafórica nunca se consuma: «Aquiles es como un león», en tener una gran melena, en su valor, en su nobleza: pero la palabra «como» evoca inmediatamente una distinción dimensional entre Aquiles y el león"22. Aquiles no tiene cola, por ejemplo (aunque Lezra admite que la Ilíada hubiera sido más graciosa si la tuviera...). Y, cómo no, "como" también puede adquirir otro significado cuando se usa con el subjuntivo imperfecto, donde implica una relación condicional, contingente ("como si", "como si tuviera cola..."), contrafáctica... "como" estructura una relación de identificación-desidentificación ("Aquiles se comporta como si fuera león, pero es hombre") ... como si todo "como" anticipara un "pero no".

Para apoyar su argumento, concluye interpretando una escena de Hamlet, en la que los personajes buscan identificar al fantasma del padre del héroe epónimo. "Marcelo dice sobre el fantasma: «¿No es como el rey?» Y Horacio responde: «Como eres contigo mismo». El «como» de Shakespeare, o de Horacio, nos presenta el espectáculo de la desarticulación de la concepción unitaria del «como», sobre la que se apoya clásicamente la

\footnotetext{
J. Lezra, Materialismo salvaje, op.cit., p. 55.

21 J. Lezra, "Like", Ponencia presentada en "Political Concepts", Brown University, 16 de noviembre de 2013, https://youtu. be/9oFUJ6CznT8.

22 Idem.
}

soberanía y el concepto de concepto"23. Me he saltado varios pasos del argumento, o los he recorrido demasiado rápido. Se puede resumir globalmente de la siguiente manera: de igual manera que el fantasma se parece al rey, "tú" (el "tú" es Marcelo en este caso) se parece a sí mismo. El fantasma es (como) el rey, pero también no es el rey; Marcelo es (como) Marcelo, y no lo es. Cuando atestiguamos la posibilidad del asedio, la posibilidad de que el fantasma es y no es el rey, también reconocemos la no-identidad del sujeto (el "yo ya no soy yo" de Lorca $)^{24}$. Los conceptos políticos fuertes de la subjetividad, la soberanía, la identidad, se exponen como constitutivamente imposibles: y la labor deconstructiva de tal pensar conceptual gira en torno a una palabra: la preposición "como".

Las preposiciones, para Levinas, y luego para Lezra, se vuelven protagonistas del drama sobre el otro en mí, sobre la responsabilidad y la normatividad, conceptos que conllevan en sí mismos una alteridad constitutiva, una esencia defectuosa. "En", "de", y "como" anuncian una relacionalidad entre términos, conceptos, sujetos. En el caso de Levinas, el empleo de la figura de la analogía, justo después de haber oscilado entre el rechazo ("No es una metáfora") y el uso limitado ("no es tan sólo imagen y figura"), no solamente revela una relación ambivalente con la figuración, sino que también realiza a nivel performático la alteración necesaria entre la responsabilidad para/con el otro y su tematización, entre el decir (le dire) y lo dicho (le dit). En manos de Lezra, vemos la necesidad de pasar por estas cuestiones retóricas para llevar a cabo una filosofía ético-política violenta, terrorífica, con implicaciones radicales.

Este paso a través de la retórica sugiere además una formulación o una definición háptica del pensar: sugiere que, para imaginar conceptos éticos o políticos, es necesario tocar, o dejar que (se, nos) toquen, territorios que parecen estables o autónomos (el mismo y el otro, la filosofía y la literatura, la ética y la política). De la misma manera en que "la culpabilidad" es como la túnica de Neso -que por su parte surge $d e$, o pertenece $a$, mi piel- el otro toca, habita, al sujeto. Al mismo tiempo, el discurso filosófico toca, y es tocado por, el lenguaje figurativo; y el pensamiento político revela el imperativo ético no como alternativo sino como constitutivo: no hay política sin ética. Y si bien estos encuentros táctiles pueden entenderse como encuentros amorosos o eróticos, también son sumamente traumáticos, terroríficos, dolorosos, como la túnica envenenada.

Abrimos con la lectura atómica, materialista, de Lucrecio, Marx y Althusser; cerramos con la ética háptica, violenta, de Sófocles, Shakespeare, y Levinas. Los sentidos como lectores salvajes nos han guiado por escenas cuya yuxtaposición incómoda nos abre caminos tanto conceptuales como metodológicos. He querido sugerir cómo la primera lleva, como método principal, a la segunda. Paso, pues, desde la lectura detenida a la dimensión ética en los textos de Lezra. Y en la obra posterior a Materialismo salva-

\footnotetext{
23 Idem.

24 F. García Lorca, "Romance sonámbulo", Romancero gitano, Nueva York, Penguin Editions, pp. 13-17.
} 
je, diremos que los conceptos defectuosos que Lezra elabora acaso flotan como motas de polvo en el aire, a la espera de que nuestros sentidos los perciban, los pongan en contacto entre sí y con las circunstancias que habitamos, y les den sentido efímero, y dado el caso, valores de norma y cualidad de institución, también, cómo y como no, efímeras.

¿Podría haber acontecido de otra manera?

\section{Bibliografía}

Barad, K., "On Touching-The Inhuman That Therefore I Am", differences: A Journal of Feminist Cultural Studies, 23.3, 2012, pp. 206-223.

Coccia, K., La vida sensible, trad. María Teresa D’Meza, Buenos Aires, Argentina, Marea, 2011.

Derrida, J., De la gramatología, trad. Oscar del Barco, México, Siglo XXI Editores, 1979.

-, "La violencia y la metafisica", en J. Derrida, La escritura y la diferencia, trad. Patricio Peñalver, Barcelona, Anthropos, 1989.

García Lorca, F." "Romance sonámbulo", en Romancero gitano, Nueva York, Penguin Editions, pp. 13-17.

Levinas, E., De otro modo que ser, o más allá de la esencia, Salamanca, Editoriales Sígueme, 4ta edición, 2003.

Lezra, J., "Like", Ponencia presentada en "Political Concepts", Brown University, 16 de noviembre de 2013, https://youtu. be/9oFUJ6CznT8.

—, Materialismo salvaje: La ética del terror y la república moderna, trad. Javier Rodríguez Fernández, Madrid, Biblioteca Nueva, 2012.

-, On the Nature of Marx's Things: Translation as Necrophilology, Nueva York, Fordham University Press, 2018.

—, República salvaje: De la naturaleza de las cosas, Santiago, Chile, Ediciones Macul, 2020.

-, Untranslating Machines: A Genealogy for the Ends of Global Thought, Londres, Rowman and Littlefield, 2017.

-, Wild Materialism: The Ethic of Terror and the Modern Republic, Nueva York, Fordham University Press, 2010.

Lucrecio Caro, T., De la naturaleza de las cosas, trad. D. José Marchena, Alicante, Biblioteca Virtual Miguel de Cervantes, 1999. http://www.cervantesvirtual.com/obra-visor/de-la-naturaleza-de-las-cosas-poema-en-seis-cantos-0/html/.

Montag, W., Althusser and His Contemporaries, Durham y Londres, Duke University Press, 2013. 